\title{
Gender Attitudes and Fertility Aspirations among Young Men in Five High Fertility East African Countries
}

\author{
Rachel C. Snow, Rebecca A. Winter, and Siobán D. Harlow
}

The relationship between women's attitudes toward gender equality and their fertility aspirations has been researched extensively, but few studies have explored the same associations among men. Using recent Demographic and Health Survey data from five high fertility East African countries, we examine the association between young men's gender attitudes and their ideal family size. Whereas several DHS gender attitude responses were associated with fertility aspirations in select countries, men's greater tolerance of wife beating was consistently associated with higher fertility aspirations across all countries, independent of education, income, or religion. Our findings highlight the overlapping values of male authority within marriage and aspirations for large families among young adult males in East Africa. Total lifetime fertility in East Africa remains among the highest worldwide: thus, governments in the region seeking to reduce fertility may need to explicitly scrutinize and address the reproduction of prevailing masculine values. (STUDIES IN FAMILY PLANNING 2013; 44[1]: 1-24)

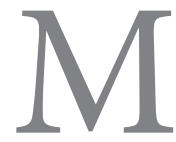

ean ideal family size is high throughout East Africa, where the lifetime total fertility rates (TFRs) of several countries are among the highest in the world. As fertility has declined in other regions, demographers and anthropologists have described the pace and nature of changing ideals of family size among many populations, highlighting the importance of women's education, better child survival, and family planning. Within this literature, considerable analysis is devoted to understanding how large family ideals are affected by structural indicators of gender equality such as women's relative educational attainment, employment status, age discordance within couples, and, more recently, attitudes toward women's decisionmaking authority and tolerance of wife beating (also referred to as tolerance of intimate partner violence) (Cleland and Wilson 1987; Diamond, Newby, and Varle 1999; Potts and Marks 2001; DeRose, Dodoo, and Patil 2002; Woldemicael 2007; Ezeh, Mberu, and

Rachel C. Snow is Research Associate Professor, Center for Population Studies, and Associate Professor, Department of Health Behavior and Health Education, University of Michigan, 3814 SPH I, 1415 Washington Heights, Ann Arbor, Michigan 48109. Rebecca A. Winter is Research Associate, ICF International, and Siobán D. Harlow is Professor, Department of Epidemiology, University of Michigan School of Public Health.E-mail: rcsnow@umich.edu. 
Emina 2009; Upadhyay and Karasek 2010; Westoff 2010). The majority of this research explores women's attitudes (Woldemicael 2007; Upadhyay and Karasek 2010; Westoff 2010).

Across many societies, a consistent inverse association exists between women's educational attainment and fertility (Cleland and Wilson 1987; Ezeh, Mberu, and Emina 2009). A recent analysis in East Africa found that temporal fertility trends across DHS waves were associated with changes in women's educational attainment, and that a positive association existed between the proportion of women having no education and stalled fertility decline in Kenya, Tanzania, Uganda, and Zimbabwe (Ezeh, Mberu, and Emina 2009). Many researchers have presented causal theories underlying the association between women's education and fertility. Based on World Fertility Survey data, Cleland and Wilson (1987) proposed that education affects women's reproductive behavior by altering ideas about their opportunities. Potts and Marks (2001) concluded that the mechanism underlying the association between education and fertility is women's enhanced status and improved bargaining power. Others have asserted that expanding freedom and educational attainment (including women's capabilities) is the best method of advancing all human development, which will inevitably lower national fertility (Anand 1994; Sen 2005; Ezeh, Mberu, and Emina 2009).

In many countries, male fertility aspirations are more highly associated with actual fertility than female aspirations (Bankole 1995), and a wife's fertility preferences are often strongly influenced by her husband's (Ezeh 1993). A significant body of work has demonstrated the important role that communication among couples plays in the effective use of fertility regulation. ${ }^{1}$ Yet research has remained sparse on the social conditions or attitudes that shape men's fertility ideals, and researchers have critiqued the embedded assumptions about men's "positionality" (culturally ascribed attributes and social position) in family planning studies as fixed or monolithic. As Basu (1999) notes, conceptual frameworks that view women's enhanced autonomy as contributing to their negotiating power rest on the assumption that universal discordant ideals regarding family size exist within any couple, with female education or empowerment brokering the difference between them. As an alternate theory to explain the observed association between education and fertility, Basu (1999) proposed that as women become more educated, their potential marriage pool shifts and they tend to marry men who are qualitatively different in their attitudes toward women and fertility from those who marry less educated women, and that such men are more likely to embrace both gender equality and smaller families. Basu (1999) provides empirical support for her theory in Southeast Asia, demonstrating that men who marry more educated spouses are more likely to have educated sisters and to endorse overlapping progressive values regarding women's empowerment and ideal family size.

In the only multivariate analysis undertaken concerning attitudinal determinants of men's ideal family size, a 1994 public opinion survey of men in five Nigerian cities reported that a greater endorsement of male-dominant gender roles was associated with a larger ideal family size (Isiugo-Abanihe 1994). Men's ideal family size was also positively associated with Muslim religious affiliation (versus Protestant), older age, and the expectation that children offer support in old age. Qualitative and mixed-method studies describe the same confluence of

1 Numerous interventions designed and introduced in the 1990s focused on building women's "negotiating power" within sexual relationships. HIV/AIDS prevention studies focused on condom negotiation, whereas other family planning projects extended the concept to promoting the use of other contraceptive methods. 
values: traditional male-dominant gender roles and the ideal of a large family (Renne 1993; Hollos and Larsen 2004; Johnson and Gu 2009).

The present study aims to describe and compare ideal family size among young men across the high fertility countries of East Africa (all with TFR > 5.0). We examine the value of the gender measures in the Demographic and Health Survey (DHS) in describing potentially related values, and test how well they are associated with ideals of family size (fertility aspirations). Relying on DHS data from five East African countries (Ethiopia, Rwanda, Tanzania, Uganda, Zambia), we characterize and compare the young men's three DHS-based gender attitudes and examine the extent to which these attitudes predict ideal number of children, net of other social factors.

We focus on young adult males aged 15-24 because they are newly entering conjugal unions and thereby testing and defining their values regarding marital gender roles, and because they are also on the cusp of parenthood. In each of the five countries, a large population cohort exists in both relative and absolute terms. With both sexes combined, the group represents between 18 and 22 percent of the total population in each of the five countries (United States Census Bureau 2005). ${ }^{2}$ Given that these young men are at the beginning of their reproductive years, their ideal family size will have important repercussions for future trends in fertility in their respective countries.

\section{CONTEXT OF HIGH FERTILITY IN EAST AFRICA}

Countries in sub-Saharan East Africa continue have some of the highest TFRs in the world (Westoff 2010). Whereas the TFR in most regions of the world has fallen to less than 3 children per woman (the TFR for 2005-10 in Asia, Central America, Europe, Latin America, North America, and South America is between 1.5 and 2.6 children per woman), the TFR for Africa is 4.6 and the TFR for East Africa is 5.1 (UNDESA 2011). The most recent TFR estimates for the five countries included in this analysis-Ethiopia, Rwanda, Tanzania, Uganda, and Zambia-are each above 5 children per woman. The highest rate is in Uganda, where women have 6.3 children on average, and the lowest is in Ethiopia, where women have 5.3 children on average (see Table 1). In both Tanzania and Ethiopia, fertility declined in the 1990s but appears to have stabilized at about 5.5 children per woman (CSA [Ethiopia] and ORC Macro 2006; TACAIDS et al. 2008). In contrast, the fertility rate in both Uganda and Rwanda remained steady in the 1990s but revealed decline in the most recent DHS survey (in Uganda fertility fell from 6.9 in 2000-01 to 6.5 in 2006, and in Rwanda fertility fell from 6.0 in 2005 to 5.5 in 2007-08) (UBOS and Macro International 2007; MOH [Rwanda], NISR, and ICF Macro 2009). Fertility in Zambia began its decline earliest, in the 1980s, but has remained close to 6 births per woman since the 1996 DHS, with a slight increase observed between the 2001-02 and 2007 surveys (CSO [Zambia] et al. 2009).

Fertility, fertility preferences, and contraceptive use have been investigated extensively in sub-Saharan Africa, yet few recent empirical studies have examined how prevailing gender values influence men's fertility aspirations (Upadhyay and Karasek 2010). Scholars across the social sciences have hypothesized that both structural and symbolic elements of African

2 The comparable percentage for the United States in the same year (2005) was 14 percent. 
society-for example, bridewealth, marriage, lineage, and extended family networks-perpetuate a marital culture of male domination that affirms and serves male preferences in African households today (Isiugo-Abanihe 1994; Bankole 1995; Bawah et al. 1999; Dodoo 2001; DeRose, Dodoo, and Patil 2002; Hollos and Larsen 2004; Dodoo and Frost 2008). ${ }^{3}$ Yet evidence also exists of emergent changes in gender values, marital roles, and family structures in Africa. Hollos and Larsen (2004) describe the recent acceptance of two distinct types of marriage among the Pare community in Tanzania: one sustaining patriarchal structures and a desire for large families, and a second characterized by companionate marriage ${ }^{4}$ and a preference for smaller families. Drawing upon a variety of demographic sources from West Africa, Locoh and Mouvagha-Sow (2004) describe measurable changes in the patriarchal and lineage model of the African family during the past quarter-century, including a decline in rigid family living arrangements; an increase in companionate marriage; an increase in informal, economically vulnerable households (for example, single mothers); and a declining preference for many children (Locoh 1996 and 2002; Locoh and Mouvagha-Sow 2004).

Locoh and Mouvagha-Sow (2004) suggest that the greatest uncertainty in the future of African families lies in the future of gender attitudes and how young people value unequal gender relations (relations that presume male authority and female submission) (Renne 1993), which have been the foundation of African marriage. Studies conducted in Kenya, South Africa, and Tanzania suggest that changing gender roles within African marriage are not all voluntary or without stress. Economic hardship and widespread unemployment are said to be reducing the chances that young men in Africa can exert their traditional masculine identity by acting as providers and protectors of a family (Silberschmidt 2001; Hunter 2005), challenging other dimensions of conformity.

New DHS variables regarding gender attitudes make possible the examination of young men's gender attitudes as potential determinants of their fertility aspirations. Since 1999-2000 the DHS has been collecting data about the relative authority of husbands and wives within marriage, and support of wife beating to enforce those norms. In the female DHS questionnaire, variables include a woman's decisionmaking authority and her attitudes toward wife beating and the right to refuse sex. In the male questionnaire, all three domains are addressed as questions of attitude; that is, women's questions about decisionmaking behavior are transformed into questions about men's attitudes toward women's decisionmaking authority. The DHS is one of several multinational surveys, including the World Values Survey (WVS) and the Gender Equity Measures Scale (GEMS), that now include gender attitude measures. ${ }^{5}$

One of these DHS gender measures - tolerance of wife beating-has been the subject of recent cross-national public health scrutiny because of increased interest in the determinants of

3 The custom of bridewealth, for example, in which the groom offers a sum of money or goods to the bride's family before marriage, has been shown to elicit a subservient disposition, or indebtedness, in the wife toward her husband. This is understood and sanctioned by both partners (Bawah et al. 1999; Frost and Dodoo 2010).

4 In companionate marriage, partners are more likely to have chosen their spouse and to share relationship power; the conjugal ties between partners are stronger and are no longer eclipsed by ties to the extended family (Locoh 2002).

5 The WVS includes a five-item gender-equality scale focused on men's and women's value in society as political leaders, breadwinners, and (for women) reproducers. The scale has been applied in at least 61 countries (Inglehart and Norris 2005), but includes no data about fertility ideals or aspirations and has limited representation in Africa. The GEM Scale, which focuses heavily on the prevailing norms of masculinity and exposure to and perpetration of violence but contains no data about fertility aspirations, has been used in two African countries (South Africa and Ethiopia). 
intimate-partner violence (IPV) ${ }^{6}$ and recognition that tolerant attitudes toward violence enable (or predict) the use of violence (Briere 1987; Heise 1998; Markowitz 2001; Murnen, Wright, and Kaluzny 2002; Flood and Pease 2009). Considerable evidence indicates that greater tolerance for wife beating is highly correlated with men's identification with more traditional gender values in general and more conservative ideals of masculine and feminine roles in marriage (Haj-Yahia 2003; Abrahams et al. 2006; Steinmetz and Haj-Yahia 2006; Flood and Pease 2009). In a comprehensive review of social attitudes that covary with men's attitudes toward IPV, Flood and Pease (2009) describe a strong positive association between men's tolerant attitudes toward domestic violence against women and more patriarchal and sexist attitudes toward gender equality, but they have not extended that analysis to attitudes regarding family size. Although the majority of their evidence is drawn from surveys of college students in western countries, they report similar findings from distinct cultural-demographic groups in Israel and Palestine (Haj-Yahia 2003; Steinmetz and Haj-Yahia 2006) and South Africa (Abrahams et al. 2006). Violent action and tolerant attitudes toward violence are predicted by exposure to violence in the childhood community (Carrington and Scott 2008; Stewart and Simons 2010), or childhood household (Briere 1987; Markowitz 2001; Lichter and McCloskey 2004).

The current study documents how young adult men across five East African countries describe their attitudes toward male domination in marriage, and the extent to which these indices of men's attitudes predict their ideal family size after adjusting for economic and social covariates (for example, wealth, education, sisters' level of education). Special emphasis is placed on the attitudes toward spousal violence, given the demonstrated utility of this variable as an indicator of traditional gender attitudes in previous studies (Haj-Yahia 2003; Abrahams et al. 2006; Steinmetz and Haj-Yahia 2006; Flood and Pease 2009). Although lack of data concerning prior family or community exposure to violence limits our ability to examine the roots of young men's attitudes, we were able to compare responses with each of three gender measures across the five countries, and examine each in relation to ideal family size, first independently, and subsequently in mixed models. Second, we compare the relative significance of the different gender measures in predicting men's ideal family size across the five countries. Third, we examine the value of the simple binary index of tolerance of wife beating ( $1=$ tolerates IPV for any of 5 reasons; $0=$ does not tolerate IPV for any of 5 reasons) in predicting men's fertility aspirations, independent of demographic factors, first by country, and then using a pooled cross-country dataset to assess the extent to which the magnitude of association varies by country. To our knowledge, this is the first study to assess the relationship between gender-equality attitudes and fertility aspirations among young men in East Africa.

\section{DATA AND METHODS}

The data for this cross-sectional study are drawn from five recent Demographic and Health Surveys from high fertility countries in East Africa: Ethiopia (2005), Rwanda (2005), Tanzania (2004-05), Uganda (2006), and Zambia (2007). The DHS is a nationally representative, pop-

6 Note, in particular, the first WHO-sponsored multicountry study on domestic violence (Garcia-Moreno et al. 2005), as well as the growing body of work from South Africa (Abrahams et al. 2006; Jewkes et al. 2008a; Jewkes, Wood, and Duvvury 2008b). 
ulation-based household survey that monitors reproductive health behaviors, attitudes, and outcomes, demographic trends, and social and background characteristics of men and women of reproductive age. DHS surveys have been conducted in more than 85 countries by national institutions in partnership with ICF Macro International and the United States Agency for International Development (USAID). All data are collected in face-to-face household interviews, and a standard core questionnaire is included in each survey, enabling cross-country analysis. Multistage cluster sampling techniques were implemented for each survey included in our analysis. In the first sampling stage, each country is stratified into major regions and census-based geographic enumeration areas are selected, with a probability of selection proportional to their size. In the second sampling stage, households are randomly selected from a list of all households within each selected enumeration area. Urban and less populated areas are oversampled to enable representative regional and rural/urban comparison. This study takes advantage of three series of gender-related questions that were incorporated into the core DHS questionnaire in 1999-2000.

All United Nations-designated East African countries meeting all three of the following conditions were included in our analysis: (1) the total fertility rate was greater than 5.0 children per woman, based on 2008 estimates; (2) the men's DHS survey data was from 2005 or later; and (3) coverage of key gender-related variables was adequate. Of the $13 \mathrm{UN}$-designated East African countries, five were excluded because their 2008 total fertility was less than 5.0 children per woman (Burundi, Eritrea, Kenya, Madagascar and Zimbabwe), and three high fertility countries were excluded for lack of DHS data since 2005 (Malawi, and Mozambique, and Somalia).

Characteristics of the five countries included in this analysis are presented in Table 1 . Because we were interested in characterizing the attitudes and context of young men in countries having persistent high fertility, our study population was restricted to men aged 15-24. Limiting the study to young men, of whom more than 80 percent were unmarried (ranging from 81 percent in Uganda to 91 percent in Rwanda), enabled us to isolate men's attitudes from the attitudes of future spouses and the experience of having children. Our final dataset of 9,056 men includes 2,399 from Ethiopia, 2,048 from Rwanda, 1,130 from Tanzania, 997 from Uganda, and 2,482 from Zambia. We consider our sample to be representative of and generalizable to young men aged 15-24 in each of these five countries. Our pooled analysis enabled comparison of intercountry differences and provided sufficient power for the examination of interaction effects, but we made no attempt to generalize our findings to the East African region overall.

\section{Variables and Measurement}

Our dependent variable-men's ideal number of children-has been widely used as a measure of fertility aspirations (Woldemicael 2007; Johnson and Gu 2009; Upadhyay and Karasek 2010; Westoff 2010). Ideal number of children was assessed similarly across each country by two questions. For men having no children, the question was phrased, "If you could choose exactly the number of children to have in your lifetime, how many would that be?" And for men having living children, the question was phrased, "If you could go back to the time when you did not have any children and could choose exactly the number of children to have in your 
lifetime, how many would that be?" (Johnson and Gu 2009). Numeric responses greater than 50 were coded as missing, as recommended by ORC Macro. Nonnumeric responses, such as "It is in the hands of God," were coded as missing, although we recognize this as a potential source of bias (Westoff 2010). Between 0.5 and 4 .1 percent of men offered a nonnumeric response to this item, and the highest proportions of nonnumeric responses were in Ethiopia (3.8 percent) and Zambia (4.1 percent). Ideal family size was missing for 99 men in Ethiopia, 14 men in Rwanda, 26 men in Tanzania, 95 men in Uganda, and 3 men in Zambia.

Our primary indicator of male-dominant attitudes was a binary measure of men's tolerance for wife beating. Measurement was based on a series of five DHS items. All DHS respondents were asked, "Sometimes a husband is annoyed or angered by things which his wife does. In your opinion, is a husband justified in hitting or beating his wife in the following situations?" DHS respondents were then presented with the following scenarios: "If the wife burns the food," "If the wife argues with the husband," "If the wife goes out without informing the husband," "If the wife neglects the children," and "If the wife refuses to have sexual relations with the husband" (Westoff 2010). A summary measure for tolerance of wife beating was created, comparing those who agreed with at least one justification for wife beating with those who did not agree with any of the five scenarios. Respondents having partial or missing data were included if they responded "yes" to any of the five instances. Respondents with missing data for all items were coded as missing and were excluded from our regression analyses. This variable was missing for less than ten men in each country.

We examined two additional measures of gender attitudes available in the DHS. We constructed a summary measure to distinguish men who agree that a husband should have at least one sexual right over his wife from all other men. This item was derived from the following DHS question sequence: "Do you think that if a woman refuses to have sex with her husband when he wants her to, he has the right to: (a) get angry and reprimand her, (b) refuse to give her money or other means of support, (c) use force and have sex with her even if she does not want to, or (d) go ahead and have sex with another woman?" (UBOS and Macro International 2007). Missing values for this indicator ranged from 74 in Uganda to 218 in Ethiopia. Our second measure of gender attitudes was based on the following DHS question: "In a couple, who do you think should have the greater say in each of the following decisions: the husband, the wife, or both equally." This question was asked of five decisions, but commentary on these items has discouraged the inclusion of all five items in one summary measure, because decisionmaking in these various realms could conflate women's autonomy with responsibility (Basu and Koolwal 2005). Based on this critique, we eliminated two items regarding household purchasing. We limited our analysis to men who agree that a husband should be the primary decisionmaker in at least one of the following three decisions: (1) what to do with the wife's earnings, (2) how many children to have, and (3) visits to the wife's family or friends. We reasoned that men who do not report that a husband should have the final say in any of these instances may have different ideas about male dominance and female subordination than men who agree with at least one. Missing values for this indicator ranged from 23 men in Uganda to 338 men in Ethiopia.

Our analysis was adjusted for demographic factors that are likely to confound the association between gender attitudes and fertility aspirations, as per the literature. An indicator variable was created for place of residence (rural/urban), marital status (never/ever married), and parity (none/one or more living children). A composite wealth index constructed by DHS 
Measure is based on household-level data concerning assets, services, and amenities, and ranks households into quintiles of level of wealth (Rutstein 2008). Religion was assessed using indicator variables for Catholic/Orthodox, Protestant, Muslim, and other religious affiliations. The groups in the "Other" category varied by country and included a combination of traditional faith, no religion, Seventh-Day Evangelist, or unspecified religion. For educational attainment, we collapsed a five-level measure into three levels, comparing men who lack formal education, men who have had some or have completed primary education, and men who have had some secondary education or higher. Because of their age, not all men in this sample have had the opportunity to complete their education, thus we adjusted for age in our multivariate analysis. Finally, we computed the mean educational attainment of all women older than 15 years who were usual residents in the household of the male respondent. Age 15 was selected as a cutoff to ensure that women included in this measure have had the opportunity to achieve a high level of education. Based on a publication by Basu (1999), we theorized that men raised in a household tolerant of women's education may be more tolerant of women's empowerment and autonomy, and have less male-dominant attitudes, compared with men raised in households in which women's education was either not valued or not accessible. Men who did not have a female household member older than 15 years were excluded from the analyses using this variable. This resulted in the exclusion of 130 cases in Ethiopia, 203 cases in Rwanda, 95 cases in Tanzania, 113 cases in Uganda, and 228 cases in Zambia.

Men's employment status (currently employed/other) and position in the household (head of household/living in parent's household/living in other household) were highly correlated with marital status and parity. Number of household members and radio exposure (examined as continuous measures) did not remain predictive of fertility aspirations in an adjusted model (data not shown).

\section{Analyses}

All analyses used a design-based approach that accounted for the nonrandom multistage DHS sample design, including its stratification and clustering (Oyeyemi, Adewara, and Adeyemi 2010). DHS sample weights were applied to all frequency calculations and regression models to correct for differences in probability of selection between cases in the sample (Rutstein and Rojas 2006). Simple weighted descriptive statistics were calculated for all variables, stratified by country. Cross-tabulations were used to assess bivariate associations between all combinations of demographic characteristics and gender attitudes to identify potential collinearity between covariates. Rao-Scott chi-square tests assessed the significance of these associations. Linear regression models were fitted to assess country-specific bivariate associations between mean ideal number of children and each demographic characteristic and gender attitude. Using logistic regression models, we assessed the adjusted association between wife-beating tolerance and other measures of male-dominant attitudes.

Multiple linear regression was used to model determinants of men's ideal number of children, separately by country and using a pooled multicountry sample. Although we considered using nonlinear modeling (for example, Poisson regression) to model ideal family size, we chose linear regression because the distribution of ideal family size was approximately normal in all five countries, and the precedent has been to use linear regression models to examine 
ideal family size. A backward model selection process was used to build the most parsimonious demographic model to predict men's fertility aspirations in each country. We began with all demographic factors that were statistically significant in crude analyses in any country, and removed nonsignificant covariates sequentially, based on Wald statistics (alpha $=0.05$ ). To facilitate intercountry comparison, final models include all demographic factors that remained a significant predictor in any country. We then added gender attitude measures to this demographic model. We assessed (and provide results for) the relative contribution of each gender measure to predict men's ideal family size. Our principle focus, however, was on the extent to which men's attitudes toward wife beating predicted ideal family size, given our hypothesis that endorsement of men's right to beat their wives is more emblematic of men's belief in their conjugal power than other gender measures in the DHS. In subsequent models, wife-beating tolerance is used as the sole indicator of male-dominant attitudes.

Because of substantial missing cases in one covariate of interest (women's mean educational attainment in the household), we assessed all associations with and without this covariate to ensure that findings were not biased by the reduction in sample. We used a pooled crosscountry dataset to assess the extent to which the impact of wife-beating tolerance depended on country or demographic factors. Interaction terms were created for wife-beating tolerance and country. To identify violations of the assumptions of the linear model, we examined the normality and homoscedasticity of residuals, assessed the influence of individual observations using Cook's Distance statistic, and evaluated potential collinearity using variance inflation statistics. All data management and analyses were conducted using survey procedures in SAS version 9.2. An alpha of 0.05 was used for all analyses.

\section{RESULTS}

Characteristics of the five countries included in this analysis are presented in Table 1. Estimates for 2008-based total lifetime fertility ranged from 5.3 in Ethiopia to 6.3 in Uganda. Mean ideal number of children among men aged 15-24 ranged from 3.8 in Rwanda to 4.8 in Tanzania. In all countries, young men's mean desired number of children was lower than the national TFR by roughly one child.

TABLE 1 Ideal number of children among men and women aged 15-24 and 25-49, total fertility rate, GNI per capita, and sample size, five selected East African countries, 2004-07

\begin{tabular}{|c|c|c|c|c|c|c|c|c|c|}
\hline \multirow[b]{3}{*}{ Country } & \multirow{3}{*}{$\begin{array}{l}\text { DHS } \\
\text { survey } \\
\text { year }\end{array}$} & \multicolumn{4}{|c|}{ Ideal number of children } & \multirow{3}{*}{$\begin{array}{r}\text { National } \\
\text { TFR }\end{array}$} & \multirow{3}{*}{$\begin{array}{l}\text { GNI per } \\
\text { capita (\$) }\end{array}$} & \multirow{2}{*}{\multicolumn{2}{|c|}{$\mathrm{N}$ for men aged $15-24$}} \\
\hline & & \multicolumn{2}{|c|}{ Men } & \multicolumn{2}{|c|}{ Women } & & & & \\
\hline & & $15-24$ & $25-49$ & $15-24$ & $25-49$ & & & Unweighted & Weighted \\
\hline Ethiopia & 2005 & 3.9 & 5.8 & 3.6 & 5.1 & 5.3 & 330 & 2,317 & 2,399 \\
\hline Rwanda & 2005 & 3.8 & 4.0 & 4.2 & 4.3 & 5.4 & 490 & 2,030 & 2,048 \\
\hline Tanzania & 2004-05 & 4.8 & 5.7 & 4.4 & 5.4 & 5.6 & 500 & 1,136 & 1,130 \\
\hline Uganda & 2006 & 4.6 & 6.5 & 4.2 & 5.6 & 6.3 & 460 & 979 & 997 \\
\hline Zambia & 2007 & 4.2 & 5.4 & 3.9 & 5.2 & 5.8 & 960 & 2,477 & 2,482 \\
\hline
\end{tabular}

NOTES: All data were drawn from selected DHSs except those for National TFR, which were drawn from the United Nations Children's Fund (UNICEF) for 2008 and gross national income (GNI) per capita, which were drawn from the World Bank for 2009. GNI per capita is the sum of value added by all resident producers, plus product taxes not included in the valuation of output, and net receipts of primary income from abroad. GNI was converted to US\$ using the World Bank Atlas method, divided by midyear population. 


\section{Gender Attitudes and Life Context of Young Men}

Table 2 presents weighted prevalence estimates for gender attitudes and demographic characteristics among men aged 15-24 in the five countries. Men's gender attitudes varied considerably across countries. Tolerance of wife beating ranged from 40 percent in Rwanda to 68 percent in Uganda. Agreement that a husband should have the final say in at least one decision was lowest in Ethiopia (35 percent) and highest in Tanzania (83 percent). Agreement that a husband should have at least one of four sexual rights over his wife ranged from 32 percent in Ethiopia to 66 percent in Tanzania (see Appendix Table A1 for results for individual components of gender attitude indicators).

TABLE 2 Weighted percentage of men aged 15-24, by gender attitudes and demographic characteristics, five selected East African countries, 2004-07

\begin{tabular}{|c|c|c|c|c|c|c|c|c|c|c|}
\hline \multirow[b]{2}{*}{ Characteristic } & \multicolumn{2}{|c|}{ Ethiopia } & \multicolumn{2}{|c|}{ Rwanda } & \multicolumn{2}{|c|}{ Tanzania } & \multicolumn{2}{|c|}{ Uganda } & \multicolumn{2}{|c|}{ Zambia } \\
\hline & $(\mathbf{n})$ & Percent & (n) & Percent & $(\mathbf{n})$ & $\overline{\text { Percent }}$ & (n) & $\overline{\text { Percent }}$ & (n) & Percent \\
\hline \multicolumn{11}{|l|}{ Gender attitudes } \\
\hline $\begin{array}{l}\text { Agrees that wife beatin } \\
\text { is justified in at least } \\
\text { one instance }\end{array}$ & $(1,250)$ & 52.1 & $(813)$ & 39.7 & (571) & 50.6 & (673) & 67.5 & $(1,326)$ & 53.6 \\
\hline $\begin{array}{l}\text { Agrees that a husband } \\
\text { has final say in at least } \\
\text { one decision }\end{array}$ & $(713)$ & 34.6 & $(960)$ & 56.6 & (914) & 83.3 & (774) & 79.5 & $(1,724)$ & 71.5 \\
\hline $\begin{array}{l}\text { Agrees that a husband } \\
\text { has at least one sexual } \\
\text { right over wife }\end{array}$ & $(697)$ & 32.0 & $(708)$ & 36.3 & $(693)$ & 65.5 & $(524)$ & 56.7 & $(1,149)$ & 47.8 \\
\hline \multicolumn{11}{|c|}{ Demographic characteristic } \\
\hline Urban & $(431)$ & 18.0 & $(345)$ & 16.8 & $(317)$ & 28.1 & $(185)$ & 18.5 & $(1,187)$ & 47.8 \\
\hline \multicolumn{11}{|l|}{ Wealth quintile } \\
\hline Lowest & $(425)$ & 17.7 & $(364)$ & 17.8 & $(220)$ & 19.5 & $(151)$ & 15.1 & $(396)$ & 16.0 \\
\hline Second & $(421)$ & 17.6 & $(359)$ & 17.5 & $(210)$ & 18.6 & $(201)$ & 20.1 & $(304)$ & 12.2 \\
\hline Middle & $(391)$ & 16.3 & $(435)$ & 21.3 & (209) & 18.5 & (178) & 17.8 & $(450)$ & 18.1 \\
\hline Fourth & (493) & 20.6 & (419) & 20.5 & $(221)$ & 19.5 & $(212)$ & 21.2 & $(583)$ & 23.5 \\
\hline Highest & $(669)$ & 27.9 & $(471)$ & 23.0 & $(270)$ & 23.9 & $(256)$ & 25.7 & (749) & 30.2 \\
\hline \multicolumn{11}{|l|}{ Religion } \\
\hline Catholic/Orthodox & $(1,240)$ & 51.7 & $(1,012)$ & 49.4 & $(344)$ & 30.4 & $(405)$ & 40.7 & $(558)$ & 22.5 \\
\hline Protestant & $(416)$ & 17.3 & $(700)$ & 34.2 & $(316)$ & 28.0 & $(363)$ & 36.4 & $(1,873)$ & 75.6 \\
\hline Muslim & $(673)$ & 28.0 & $(46)$ & 2.2 & (329) & 29.1 & $(147)$ & 14.7 & (12) & 0.50 \\
\hline Other & $(71)$ & 3.0 & $(290)$ & 14.1 & $(141)$ & 12.5 & $(82)$ & 8.2 & (34) & 1.4 \\
\hline \multicolumn{11}{|l|}{ Education } \\
\hline None & $(630)$ & 26.3 & (195) & 9.53 & $(122)$ & 10.8 & (14) & 1.4 & (59) & 2.4 \\
\hline $\begin{array}{l}\text { Partial or complete } \\
\text { primary }\end{array}$ & $(1,135)$ & 47.3 & $(1,655)$ & 80.8 & $(884)$ & 78.2 & $(666)$ & 66.8 & $(1,112)$ & 44.8 \\
\hline $\begin{array}{l}\text { Partial or complete } \\
\text { secondary+ }\end{array}$ & $(634)$ & 26.4 & (198) & 9.66 & $(124)$ & 11.0 & $(317)$ & 31.8 & $(1,311)$ & 52.8 \\
\hline \multicolumn{11}{|c|}{$\begin{array}{l}\text { Mean educational attainment } \\
\text { of women in household (years) }\end{array}$} \\
\hline$\leq 1$ & $(1,617)$ & 71.3 & $(609)$ & 33.0 & $(269)$ & 26.0 & $(211)$ & 23.9 & $(261)$ & 11.6 \\
\hline $1-5$ & $(436)$ & 19.2 & $(782)$ & 42.4 & (313) & 30.2 & $(281)$ & 31.8 & $(418)$ & 18.5 \\
\hline $5+$ & $(216)$ & 9.5 & $(454)$ & 24.6 & $(453)$ & 43.8 & $(392)$ & 44.3 & $(1,576)$ & 69.9 \\
\hline Ever married & $(318)$ & 13.3 & (185) & 9.0 & (179) & 15.8 & $(187)$ & 18.7 & $(328)$ & 13.2 \\
\hline $\begin{array}{l}\text { Parity of one or more } \\
\text { children }\end{array}$ & $(158)$ & 6.6 & $(150)$ & 7.3 & $(117)$ & 10.3 & $(146)$ & 14.6 & (299) & 12.1 \\
\hline \multicolumn{11}{|l|}{ Age (years) } \\
\hline $15-19$ & $(1,335)$ & 55.7 & $(1,102)$ & 53.8 & $(637)$ & 56.4 & $(595)$ & 59.7 & $(1,416)$ & 57.0 \\
\hline $20-24$ & $(1,064)$ & 44.3 & (946) & 46.2 & (493) & 43.6 & $(402)$ & 40.3 & $(1,066)$ & 43.0 \\
\hline
\end{tabular}


The demographic composition of young men varied meaningfully across countries. Whereas the rural-urban composition of young men was similar in Ethiopia, Rwanda, and Uganda, ranging from 17 percent to 19 percent urban, the young male populations of Tanzania and Zambia were more urban ( 28 percent and 48 percent, respectively). In all countries, the young male population was slightly wealthier than the household-derived DHS wealth quintiles, either indicating that young men were at a wealth advantage or that wealthier households had more members than poorer households. Educational attainment was highest in Zambia, where 53 percent of young men had at least some secondary education, compared with 10 percent and 11 percent in Rwanda and Tanzania, respectively. The proportion of young men having no education ranged from 1-2 percent in Uganda and Zambia, to greater than 25 percent in Ethiopia. In all countries, the majority of young men had never been married (81-91 percent) and had no living children (85-93 percent).

The mean educational attainment of women in men's households varied widely across the five countries. Ethiopia had the lowest female educational attainment in men's households. Whereas 71 percent of men in Ethiopia come from households where the mean educational attainment of women was less than one year, only 12 percent of men in Zambia came from such households.

\section{Ideal Family Size}

Table 3 presents unadjusted weighted associations between young men's ideal number of children and their gender attitudes and demographic characteristics. Overall, the direction of association between gender attitudes and ideal family size was similar across the five countries, such that each measure of male dominance was positively associated with men's fertility aspirations. Wife-beating tolerance was associated with the addition of between 0.40 and 0.86 children to men's ideal number of children. Attitudes toward a husband's decisionmaking power and sexual rights were significant predictors in all countries except Uganda.

The direction of the association between demographic characteristics and ideal family size was generally consistent across the five countries, although the magnitude of the associations varied. Urban residence was consistently associated with smaller ideal family size, such that men residing in urban households desired between 0.4 (in Rwanda) and 1.5 (in Tanzania) less children than rural men. The threshold and pattern of association for wealth differed by country. In Ethiopia, men in the lowest wealth quintile stood apart, desiring roughly two more children than all other quintiles, whereas in Tanzania such a large reduction in desired family size was observed in only the highest quintile. Having no education was significantly associated with wanting more children in Ethiopia and Tanzania. This association was strongest in Tanzania, where men having no education wanted nearly three more children than men having some or complete primary education.

In all countries, higher mean educational attainment of women in the men's household was significantly associated with lower fertility aspirations in men. For each additional year of education among women in the household, men desired between 0.07 (in Rwanda) and 0.18 (in Tanzania) fewer children. Based on these findings, men in Tanzania from households in which women have no education would be expected to want nearly one child more than men from households where women had an average of six years of education. In Ethiopia, Rwanda, 
TABLE 3 Beta coefficients from unadjusted regression representing the influence of various gender attitudes and demographic characteristics on ideal number of children among men aged 15-24, five selected East African countries, 2004-07

\begin{tabular}{|c|c|c|c|c|c|}
\hline Characteristic & Ethiopia & Rwanda & Tanzania & Uganda & Zambia \\
\hline \multicolumn{6}{|l|}{ Gender attitude } \\
\hline Wife-beating tolerance & $0.594^{* * * *}$ & $0.594^{* * * *}$ & $0.863^{* * * *}$ & $0.399^{* *}$ & $0.450^{* * * *}$ \\
\hline Decisionmaking authority & $0.683^{* * *}$ & $0.202^{*}$ & $0.721^{* * *}$ & 0.034 & $0.376^{* * *}$ \\
\hline Husband's sexual rights & $0.666^{* * *}$ & $0.430^{* * * *}$ & $0.515^{\star *}$ & 0.238 & $0.331^{\star * * *}$ \\
\hline \multicolumn{6}{|l|}{ Demographic characteristic } \\
\hline \multicolumn{6}{|l|}{ Residence } \\
\hline Rural (r) & 0.000 & 0.000 & 0.000 & 0.000 & 0.000 \\
\hline Urban & $-1.196^{* * * *}$ & $-0.405^{\star *}$ & $-1.480^{* * * *}$ & $-0.832^{\star * * *}$ & $-1.029^{* * * *}$ \\
\hline \multicolumn{6}{|l|}{ Wealth quintile } \\
\hline Lowest (r) & 0.000 & 0.000 & 0.000 & 0.000 & 0.000 \\
\hline Second & $-1.880^{* * * *}$ & -0.180 & -0.456 & -0.147 & -0.339 \\
\hline Middle & $-1.991^{\star * * *}$ & -0.025 & $-0.825^{\star}$ & -0.276 & $-0.589^{* *}$ \\
\hline Fourth & $-2.019^{* * * *}$ & -0.196 & $-1.013^{*}$ & -0.528 & $-1.287^{\star * * *}$ \\
\hline Highest & $-2.490^{* * * *}$ & $-0.623^{\star * * *}$ & $-2.173^{* * * *}$ & $-0.766^{* *}$ & $-1.592^{\star * * *}$ \\
\hline \multicolumn{6}{|l|}{ Religion } \\
\hline Catholic/Orthodox (r) & 0.000 & 0.000 & 0.000 & 0.000 & 0.000 \\
\hline Protestant & $0.413^{* *}$ & 0.010 & 0.061 & -0.009 & $0.269^{* *}$ \\
\hline Muslim & $1.221^{\star * *}$ & 0.038 & 0.216 & 0.135 & -1.012 \\
\hline Other & 2.116 & 0.175 & $3.063^{* * * *}$ & 0.278 & 0.347 \\
\hline \multicolumn{6}{|l|}{ Education } \\
\hline None & $1.474^{* * * *}$ & -0.060 & $2.764^{* * * *}$ & 2.399 & 0.488 \\
\hline Partial or complete primary $(r)$ & 0.000 & 0.000 & 0.000 & 0.000 & 0.000 \\
\hline Partial or complete secondary+ & $-0.523^{* * * *}$ & $-0.662^{* * * *}$ & $-1.139^{* * * *}$ & -0.209 & $-0.809^{* * * *}$ \\
\hline $\begin{array}{l}\text { Mean educational attainment } \\
\text { of women in household }\end{array}$ & $-0.157^{* * * *}$ & $-0.072^{* * * *}$ & $-0.176^{* * * *}$ & $-0.105^{* * * *}$ & $-0.126^{* * * *}$ \\
\hline Ever married & $1.052^{\star * *}$ & 0.191 & 0.525 & -0.046 & $0.503^{\star *}$ \\
\hline Parity & $1.298^{* * * *}$ & $0.294^{*}$ & 0.266 & -0.096 & $0.302^{*}$ \\
\hline Age & 0.041 & $-0.049^{* *}$ & -0.012 & -0.0152 & -0.001 \\
\hline Weighted sample size ${ }^{a}$ & $(2,300)$ & $(2,034)$ & $(1,104)$ & $(992)$ & $(2,389)$ \\
\hline
\end{tabular}

${ }^{*}$ Significant at $\mathrm{p}<0.05 ;{ }^{* *} \mathrm{p}<0.01 ;{ }^{* * *} \mathrm{p}<0.001 ;{ }^{* * * *} \mathrm{p}<0.0001 . \quad(\mathrm{r})=$ Reference category.

${ }^{a}$ For the following variables, the weighted sample size was somewhat lower: wife-beating tolerance, decisionmaking authority, husband's sexual rights, religious affiliation (Zambia only), and mean educational attainment of women in household.

and Zambia, men having living children wanted significantly more children than men having no children. Age was only a significant predictor of ideal number of children in Rwanda, where older age was associated with slightly lower fertility aspirations.

\section{Tolerance of Wife Beating as an Indicator of Male-Dominant Attitudes}

After adjusting for urban residence, wealth, educational attainment, religion, parity, and age, the odds of being tolerant of wife beating were significantly greater in all five countries among men who agreed that a husband should have at least one sexual right over his wife, compared with men who did not agree (see Table 4). The adjusted odds ratios ranged from 2.6 to 6.6. In four of the five countries (the exception being Uganda), the odds of being tolerant of wife beating were independently associated with the opinion that a husband should have the final say in at least one of three decisions, after adjusting for the same demographic characteristics. 
TABLE 4 Adjusted odds ratios among men aged 15-24 for tolerance of wife beating, by other measures of gender attitudes, five selected East African countries, 2004-07

\begin{tabular}{lccccc}
\hline Characteristic & Ethiopia & Rwanda & Tanzania & Uganda & Zambia \\
\hline Decisionmaking authority & $2.25^{\star * * *}$ & $1.45^{* *}$ & $2.47^{* * * *}$ & 1.33 & $2.64^{* * * *}$ \\
Husband's sexual rights & $6.61^{* * * *}$ & $3.51^{* * * *}$ & $2.63^{* * * *}$ & $4.00^{* * * *}$ & $3.61^{* * * *}$ \\
\hline
\end{tabular}

NOTES: Models are run separately for decisionmaking authority and husband's sexual rights. Odds ratios are adjusted for urban/rural residence, wealth (five categories), education (three categories), religion (four categories), parity (two categories), and age (continuous).

TABLE 5 Beta coefficients from adjusted regression representing relative ability of three measures of gender attitudes to predict ideal number of children among men aged 15-24, controlling for demographic factors, five selected East African countries, 2004-07

\begin{tabular}{|c|c|c|c|c|c|c|c|c|c|c|}
\hline \multirow[b]{3}{*}{ Characteristic } & \multicolumn{2}{|c|}{ Ethiopia } & \multicolumn{2}{|c|}{ Rwanda } & \multicolumn{2}{|c|}{ Tanzania } & \multicolumn{2}{|c|}{ Uganda } & \multicolumn{2}{|c|}{ Zambia } \\
\hline & \multicolumn{2}{|c|}{ Adjusted } & \multicolumn{2}{|c|}{ Adjusted } & \multicolumn{2}{|c|}{ Adjusted } & \multicolumn{2}{|c|}{ Adjusted } & \multicolumn{2}{|c|}{ Adjusted } \\
\hline & $\boldsymbol{\beta}$ & & $\beta$ & $\mathbf{R}^{2}$ & $\beta$ & & $\beta$ & $\mathbf{R}^{2}$ & $\beta$ & $\mathbf{R}^{2}$ \\
\hline $\begin{array}{l}\text { Model with men's demographi } \\
\text { characteristics only }\end{array}$ & - & 0.184 & - & 0.027 & - & 0.186 & - & 0.045 & - & 0.110 \\
\hline \multicolumn{11}{|l|}{$\begin{array}{l}\text { Adding gender attitudes } \\
\text { individually }\end{array}$} \\
\hline Wife-beating tolerance & $0.294^{*}$ & 0.187 & $0.500^{* * * *}$ & 0.044 & $0.724^{\star * * *}$ & 0.200 & $0.299^{*}$ & 0.049 & $0.235^{\star *}$ & 0.114 \\
\hline Decisionmaking authority & $0.332^{*}$ & 0.187 & 0.188 & 0.029 & 0.285 & 0.187 & -0.109 & 0.045 & 0.149 & 0.111 \\
\hline Husband's sexual rights & $0.413^{*}$ & 0.189 & $0.374^{* * *}$ & 0.036 & 0.129 & 0.186 & 0.169 & 0.046 & $0.217^{\star \star}$ & 0.113 \\
\hline Weighted sample size & \multicolumn{2}{|c|}{$(1,868)$} & \multicolumn{2}{|c|}{$(1,613)$} & \multicolumn{2}{|c|}{$(1,017)$} & \multicolumn{2}{|c|}{$(902)$} & \multicolumn{2}{|c|}{$(2,277)$} \\
\hline Extended demographic model ${ }^{\mathrm{t}}$ & - & 0.184 & - & 0.030 & - & 0.187 & - & 0.054 & - & 0.112 \\
\hline $\begin{array}{l}\text { Mean educational attainment } \\
\text { of women in household }\end{array}$ & 0.005 & - & -0.008 & - & -0.009 & - & $-0.060^{*}$ & - & -0.032 & - \\
\hline \multicolumn{11}{|c|}{ Adding gender attitudes individually } \\
\hline Wife-beating tolerance & $0.318^{*}$ & 0.187 & $0.529^{* * * *}$ & 0.050 & $0.745^{\star * * *}$ & 0.201 & $0.324^{*}$ & 0.059 & $0.238^{\star \star}$ & 0.115 \\
\hline Decisionmaking authority & 0.317 & 0.186 & $0.239^{*}$ & 0.034 & 0.298 & 0.188 & -0.048 & 0.054 & 0.130 & 0.112 \\
\hline Husband's sexual rights & 0.416 & 0.188 & $0.366^{\star *}$ & 0.039 & 0.149 & 0.187 & 0.136 & 0.055 & $0.206^{*}$ & 0.114 \\
\hline Weighted sample size & \multicolumn{2}{|c|}{$(1,755)$} & \multicolumn{2}{|c|}{$(1,434)$} & \multicolumn{2}{|c|}{$(932)$} & \multicolumn{2}{|c|}{$(802)$} & \multicolumn{2}{|c|}{$(2,066)$} \\
\hline
\end{tabular}

${ }^{\star}$ Significant at $\mathrm{p}<0.05 ;{ }^{* *} \mathrm{p}<0.01 ;{ }^{* * *} \mathrm{p}<0.001 ;{ }^{* * * *} \mathrm{p}<0.0001 . \quad-=$ Not applicable.

aThis model adjusted for urban residence (one indicator), wealth (quintiles), education (three levels), religion (Catholic/Orthodox, Protestant, Muslim, Other), parity (one indicator), and age as a continuous variable. In all models in Table 5 we used a sample restricted to men with complete data for all three gender attitude measures, for the purpose of comparison, and ran separate models for each gender attitude, to compare their relative predictive ability.

${ }^{\mathrm{b}}$ The extended demographic model adjusted for mean educational attainment of women in the household, in addition to all covariates included in the earlier demographic model. For this model we used a sample restricted to men with complete data for women's educational attainment measures, in addition to all three gender items.

After adjustment for demographic factors (top half of Table 5) and demographic factors including the educational attainment of women in the men's household (bottom half of Table 5), wife-beating tolerance remained predictive of ideal family size in all five East African countries, whereas men's attitudes toward a husband's decisionmaking authority remained predictive in one country and men's attitudes toward a husband's sexual rights remained predictive in three countries (upper model) and two countries (lower model). Given that the adjusted association between wife-beating tolerance and ideal number of children appeared more robust and consistent than associations between ideal number of children and the other gender attitude measures, and because of substantial missing data in the decisionmaking and husband's sexual rights measures, subsequent analyses used wife-beating tolerance as the indicator of male-dominant attitudes. 


\section{Multivariate Findings}

Table 6 shows the adjusted association between wife-beating tolerance and ideal number of children presented separately by country. In all countries, wife-beating tolerance remained significantly associated with young men's fertility aspirations, increasing the reported ideal number from 0.27 to 0.70 children, independent of urban residence, religious affiliation, wealth, men's educational attainment, the mean educational attainment of women in the household, parity, and age.

The sum explanatory power (that is, adjusted $\mathrm{R}^{2}$ ) of men's demographic characteristics varied considerably between countries, ranging from 5 percent in Uganda to 20 percent in Tanzania. Wealth, educational attainment, and to a lesser extent urban residence each had negative adjusted associations with men's ideal family size, but these associations were not consistently statistically significant and they varied considerably between countries. Religion was a significant predictor of men's ideal number of children in Ethiopia, Tanzania, and Zambia. In Ethiopia, Muslims and Protestants wanted more children than did Catholic or Orthodox respondents (the combined reference category) after adjusting for demographic characteristics (0.8 and 0.4 more, respectively). In Zambia, Protestants wanted 0.2 more than did Catholics/ Orthodox, and in Tanzania Catholics/Orthodox wanted 2.2 fewer children than did those in

TABLE 6 Beta coefficient representing adjusted association among men aged 15-24 between wife-beating tolerance and ideal number of children, five selected East African countries, 2004-07

\begin{tabular}{|c|c|c|c|c|c|}
\hline Characteristic & Ethiopia & Rwanda & Tanzania & Uganda & Zambia \\
\hline Wife-beating tolerance & $0.305^{\star}$ & $0.535^{* * * *}$ & $0.704^{* * * *}$ & $0.293^{*}$ & $0.266^{* *}$ \\
\hline \multicolumn{6}{|l|}{ Demographic characteristic } \\
\hline \multicolumn{6}{|l|}{ Residence } \\
\hline Rural (r) & 0.000 & 0.000 & 0.000 & 0.000 & 0.000 \\
\hline Urban & -0.339 & -0.085 & $-0.601^{\star}$ & -0.519 & -0.162 \\
\hline \multicolumn{6}{|l|}{ Religion } \\
\hline Catholic/Orthodox (r) & 0.000 & 0.000 & 0.000 & 0.000 & 0.000 \\
\hline Protestant & $0.356^{*}$ & 0.034 & -0.078 & 0.108 & $0.197^{\star}$ \\
\hline Muslim & $0.843^{* * * *}$ & 0.085 & 0.415 & 0.330 & -0.907 \\
\hline Other & 1.529 & 0.218 & $2.218^{* * * *}$ & 0.287 & 0.281 \\
\hline \multicolumn{6}{|l|}{ Wealth quintile } \\
\hline Lowest (r) & 0.000 & 0.000 & 0.000 & 0.000 & 0.000 \\
\hline Second & $-1.452^{* * * *}$ & -0.112 & -0.080 & -0.040 & -0.355 \\
\hline Middle & $-1.619^{* * * *}$ & -0.026 & -0.293 & -0.175 & $-0.521^{*}$ \\
\hline Fourth & $-1.460^{* * * *}$ & -0.085 & 0.115 & -0.328 & $-0.942^{\star * * *}$ \\
\hline Highest & $-1.362^{* * * *}$ & $-0.378^{*}$ & -0.555 & -0.236 & $-1.020^{\star * * *}$ \\
\hline \multicolumn{6}{|l|}{ Education } \\
\hline None & $1.085^{\star * \star *}$ & -0.027 & $2.122^{* * *}$ & 2.120 & 0.471 \\
\hline Partial or complete primary $(r)$ & 0.000 & 0.000 & 0.000 & 0.000 & 0.000 \\
\hline Partial or complete secondary+ & -0.079 & $-0.409^{*}$ & $-0.431^{\star *}$ & -0.085 & $-0.295^{\star *}$ \\
\hline $\begin{array}{l}\text { Mean educational attainment of } \\
\text { women in household }\end{array}$ & 0.001 & -0.032 & -0.004 & $-0.054^{*}$ & -0.031 \\
\hline Parity & $0.820^{* *}$ & 0.311 & 0.142 & -0.046 & 0.041 \\
\hline Age & 0.011 & $-0.038^{*}$ & -0.001 & -0.002 & 0.003 \\
\hline Adjusted $\mathrm{R}^{2}$ & 0.168 & 0.053 & 0.201 & 0.059 & 0.109 \\
\hline Weighted sample size & $(2,171)$ & $(1,833)$ & $(1,011)$ & $(880)$ & $(2,162)$ \\
\hline
\end{tabular}

${ }^{*}$ Significant at $\mathrm{p}<0.05 ;{ }^{* *} \mathrm{p}<0.01 ;{ }^{* * *} \mathrm{p}<0.001 ;{ }^{* * * *} \mathrm{p}<0.0001 . \quad(\mathrm{r})=$ Reference category. 
the "Other" religion category. As observed in the unadjusted results, the ideal number of children among young men in the poorest quintile in Ethiopia continued to stand apart from all other quintiles, even after adjusting for other sociodemographic factors. The stability in ideals across quintiles 2-5 in Ethiopia may reflect a limited gradient in household wealth, because Ethiopia has the lowest GDP per capita (US\$357) of the five countries (World Bank 2013). The most notable trend in ideal family size across wealth quintiles was observed in Zambia, which has the highest GDP per capita (US\$1,425) (World Bank 2013).

In the pooled dataset presented in Table 7, men's tolerance of wife beating was associated with an adjusted increase of 0.4 children. Mean educational attainment of women in the household remained a small but significant independent predictor of men's fertility aspirations, such that men from households in which women had six years of education would want on average 0.16 fewer children than men from households where women had no education,

TABLE 7 Beta coefficient from multivariate main effects model in pooled dataset of men aged 15-24 predicting ideal number of children, five selected East African countries

\begin{tabular}{|c|c|}
\hline Characteristic & $\beta$ \\
\hline Wife-beating tolerance & $0.404^{* * * *}$ \\
\hline \multicolumn{2}{|l|}{ Country } \\
\hline Ethiopia & $-0.991^{* * * *}$ \\
\hline Rwanda & $-0.811^{* * * *}$ \\
\hline Tanzania (r) & 0.000 \\
\hline Uganda & -0.063 \\
\hline Zambia & -0.026 \\
\hline \multicolumn{2}{|l|}{ Demographic characteristic } \\
\hline \multicolumn{2}{|l|}{ Residence } \\
\hline Rural (r) & 0.000 \\
\hline Urban & $-0.375^{\star * * *}$ \\
\hline \multicolumn{2}{|l|}{ Wealth quintile } \\
\hline Lowest (r) & 0.000 \\
\hline Second & $-0.608^{* * * *}$ \\
\hline Middle & $-0.679^{* * * *}$ \\
\hline Fourth & $-0.758^{* * *}$ \\
\hline Highest & $-0.844^{* * * *}$ \\
\hline \multicolumn{2}{|l|}{ Education } \\
\hline None & $1.010^{* * * *}$ \\
\hline Partial or complete primary $(r)$ & 0.000 \\
\hline Partial or complete secondary+ & $-0.221^{\star * *}$ \\
\hline Mean educational attainment of women in household & $-0.027^{\star *}$ \\
\hline \multicolumn{2}{|l|}{ Religion } \\
\hline Catholic/Orthodox (r) & 0.000 \\
\hline Protestant & $0.180^{\star *}$ \\
\hline Muslim & $0.570^{* * * *}$ \\
\hline Other & $1.011^{* * * *}$ \\
\hline Parity & $0.217^{*}$ \\
\hline Age & -0.010 \\
\hline Adjusted $\mathrm{R}^{2}$ & 0.123 \\
\hline Unweighted sample size & $(7,878)$ \\
\hline Weighted sample size & $(8,055)$ \\
\hline
\end{tabular}

${ }^{*}$ Significant at $\mathrm{p}<0.05 ;{ }^{* *} \mathrm{p}<0.01 ;{ }^{* * *} \mathrm{p}<0.001 ;{ }^{* * *} \mathrm{p}<0.0001$. $(\mathrm{r})=$ Reference category. 
after adjustment for country, urban residence, wealth, men's educational attainment, men's marital status, parity, and age. In our country-specific analysis, this adjusted association was only significant in Uganda, but the direction of the association was consistent in four of the five countries (see Table 6).

After adjusting for intercountry differences in demographic composition, the primary effect of country for Uganda and Zambia virtually disappeared, suggesting that the difference in overall mean ideal number of children between Tanzania, Uganda, and Zambia (4.8, 4.6, and 4.2 , respectively) can be explained largely by different demographic compositions between countries (see Table 1). The significant negative country effects in Rwanda and Ethiopia relative to Tanzania remain to be explained. The wealth quintiles in this analysis are only withincountry relative estimates and therefore offer no insight into the role of absolute wealth on fertility aspirations across these countries.

\section{DISCUSSION AND CONCLUSION}

In our analysis, greater tolerance of wife beating was strongly associated with fertility aspirations among young men aged 15-24, and this was consistent across five diverse East African countries. These findings support Basu's (1999) hypothesis that in some settings men who desire many children are qualitatively different from men who desire fewer children. In these five countries, young adult men having higher fertility aspirations have more male-dominant attitudes than those having lower fertility aspirations.

Our findings are in accord with a study of men's attitudes from five cities in Nigeria, which found that subscribing to values of male dominance was associated with higher fertility desires (Isiugo-Abanihe 1994), and also are compatible with the findings of several studies showing that women who express greater tolerance for wife beating have higher fertility and higher fertility aspirations (Woldemicael 2007; Upadhyay and Karasek 2010; Westoff 2010). The adjusted impact of tolerance for wife beating that we report ( 0.40 children in our pooled sample) is even higher than Isiugo-Abaniho's (1994) reported adjusted value of 0.26 children for men having male-dominant attitudes, compared with similar men with femaledominant attitudes.

The finding that women who tolerate wife-beating tend to have more children cannot be interpreted as a reflection of women's corresponding values in the same manner that we interpret such observations among men, because tolerance of wife-beating is associated with its practice, and violent households create conditions in which women are generally less free to express or assert their personal aspirations than they would be otherwise. Studies from both Ghana and India find that women with violent husbands tend to be fearful of discussing family planning and are less likely to practice contraception, leading to higher unplanned and overall fertility that does not necessarily reflect women's fertility aspirations (Bawah et al. 1999; Stephenson, Koenig, and Ahmed 2006; Wilson-Williams et al. 2008).

Our analysis also suggests that when compared with other measures of gender attitudes included in the DHS, such as the endorsement of men's sexual rights over their wife, or a husband's decisionmaking authority, men's tolerance for wife beating was the strongest predictor 
of ideal family size in all countries except Ethiopia. Our hypothesis that tolerance for wife beating offers a more consistent measure of men's attitudes toward gender equality is in keeping with Kishor and Subaiya's (2008) report that after comparing gender attitudes across DHSs in 23 low- and middle-income countries, attitudes toward both decisionmaking authority and male sexual rights varied without any apparent consistency across demographic characteristics of women, their households, or their communities (for example, wealth, age, religion, education, other gender values). Having initially hypothesized that attitudes toward male sexual rights and wife beating measured a similar ideational construct, Kishor and Subaiya (2008) acknowledged that attitudes toward wife beating and toward a woman's right to refuse sex varied considerably in their social patterning - that is, in their association with demographic factors. In fact, with the exception of educational attainment, no social characteristic was similarly associated with both attitudes toward wife beating and women's right to refuse sex, suggesting that these two responses are not measuring similar values or gender constructs across different countries (Kishor and Subaiya 2008).

Kishor and Subaiya (2008) also found that women's decisionmaking authority had little consistency across subcategories of decisionmaking (for small purchases, health care, and so forth) in different countries, and compared with the other DHS gender measures had the least predictable country-to-country variation with social correlates such as education or wealth. They concluded (page 41) that creating an aggregate index of decisionmaking authority was problematic:

Women's participation in decisionmaking is not one undifferentiated variable. For any decision, making the decision alone, making it jointly with a husband or someone else, or participating at all in the decision (alone or jointly), constitute unique variables with different correlates. This makes it difficult to treat decisionmaking as a single indicator of empowerment.

In our study, responses on the subscales of decisionmaking varied considerably within each of the five countries (see Appendix Table A1), undermining a straightforward interpretation of the proportion of men who agree that a husband should have the final say in at least one household decision (versus no decisions). In Africa, the symbolic importance of women's decisionmaking authority may also be undermined because of weak conjugal ties and the possibility that each partner makes decisions in separate spheres, whereas a wife's submission is well scripted and enacted when husband and wife are together. African market women, for example, who make their livelihoods trading goods, may have considerable decisionmaking authority over their earnings and mobility, but that does not necessarily translate into relative freedom in other aspects of their marital or sexual lives.

In addition to the standard DHS measures of gender attitudes, we examined whether the educational attainment of women in men's households may distinguish men who were raised to have a higher degree of tolerance for women's autonomy. We based this hypothesis on Basu's (1999) observation that the mean educational attainment of men's sisters positively predicted men's tolerance of women's autonomy in India. In our pooled analysis, the mean educational attainment of women in the household remained a small but significant negative predictor of men's ideal number of children, independent of country, demographic charac- 
teristics, and wife-beating tolerance. These significant findings suggest that further investigation of this measure is warranted to evaluate the extent to which it provides new insight into gender attitudes within a household.

Given the scarcity of data concerning social determinants of men's fertility aspirations, commenting on the ability of standard demographic characteristics to predict men's ideal family size is worthwhile. Overall, little consistency was found across the five countries in the predictive power of men's demographic characteristics. Higher educational attainment, greater relative wealth, and urban residence each had negative associations with men's ideal family size, but these frequently failed to achieve statistical significance in the adjusted models. In this young cohort, age and parity were not robust predictors of fertility aspirations among men, but we would expect them to become more important at older ages, as they are for women (Westoff 2010; Snow et al. 2012). The greater tolerance of wife beating in rural areas in the unadjusted data, and the consistent direction of this association (if not consistently statistically significant) in the adjusted analysis, are in keeping with earlier results from Kenya and Zambia (Lawoko 2008) and the WHO multicountry study on domestic violence (Garcia-Moreno et al. 2005). Examining whether a tolerant attitude toward wife beating reflects a normative attitude toward physical violence in general may be worthwhile. This normative attitude has been identified with rural communities characterized by lifestyles of high physical danger (Carrington and Scott 2008). Our models are adjusted for urban/rural residence, but without additional data concerning regional or community norms, the utility of this adjustment is limited.

Tolerant attitudes toward wife beating and violent behavior are highly correlated (Briere 1987; Heise 1998; Markowitz 2001; Murnen, Wright, and Kaluzny 2002; Flood and Pease 2009), although the association is stronger for males than females. The observed association between men's tolerance of wife beating and a larger ideal family size is likely to reflect ideational overlap, but it has instrumental effects. In qualitative studies conducted in Ghana and India (Bawah et al. 1999; Wilson-Williams et al. 2008), women married to violent husbands admitted fear of discussing contraception. This may explain why marriages having higher IPV exhibit less family planning behavior, more unintended pregnancies, and higher unplanned fertility (Bawah et al. 1999; Stephenson, Koenig, and Ahmed 2006; Wilson-Williams et al. 2008). Thus, simply through an expressed tolerance of wife beating, males may be able to exert greater conjugal control over family planning and fertility.

Limitations of this study are worth noting. First, the explanatory power of our final models (shown in Tables 6 and 7) is low, with final country-specific models explaining between 5 and 20 percent of the variation in young men's ideal family size. Our explanatory power is within the range reported in the fertility aspiration literature, however. In a recent DHS report exploring ideal number of children as a linear outcome among women, models were able to explain between 14 and 25 percent of the variation in ideal family size across DHS countries. Second, we recognize three potential sources of bias. We coded nonnumeric responses such as "It is in the hands of God" as missing, and these men were not included in our regression analysis. In the countries included in our analysis, $0.5-4.1$ percent of men offered a nonnumeric response to this item, with the highest proportions of nonnumeric responses in Ethiopia (3.8 percent) and Zambia (4.1 percent). The exclusion of these men could potentially have negatively biased the reported association between male-dominant attitudes and ideal number of children, given that 
(1) religious men have been shown to be more likely to provide nonnumeric responses to this question, and (2) religious men may also be more likely to desire more children and have more traditional attitudes toward male-dominance (Westoff 2010). If this were so, we could expect the true magnitude of association between gender attitudes and fertility aspirations to be greater than we report. Additionally, substantial data were missing for women's mean educational attainment in the household. To ensure that this sample restriction did not bias our findings, we ran our adjusted model-separately by country and also merged - without this covariate in both the full and restricted samples. Because the sample reduction did not change the direction of any covariate and did not substantially alter the magnitude of covariates of interest, the final model we present in Tables 6 and 7 includes the mean educational attainment of women in the household.

The DHS measure of ideal number of children has been criticized for its vulnerability to ex-post rationalization of adults who already have children (Bhushan and Hill 1996). In our restricted sample of young men, however, in which more than 85 percent have no living children, ex-post rationalization is not likely to positively bias our estimates of fertility aspirations. Nonetheless, to account for this bias, we adjust for parity in all models.

Admittedly, we have only a limited ability to measure male-dominant attitudes using DHS data. The prevailing gender norms within which a person is raised and indoctrinated are an accident of birth, with ideals of masculine and feminine behavior shaped by family and community. In some cultural environments these may be narrowly prescribed, whereas in others they may be allowed far-ranging expression. Our binary measure of wife-beating tolerance provides a crude measure of a complex, multidimensional attitude and cannot measure maledominant attitudes comprehensively. The strong correlation we documented between this measure and other available measures of gender attitudes, however, and the consistency of the association between this attitude and fertility aspirations across diverse countries suggests that it captures some meaningful dimension of the orientation of young men in these East African countries that is affecting their attachment to large family ideals.

Despite these limitations, this study has several important strengths. We used high-quality survey data that was conducted with excellent quality control and that is comparable across countries. Our primary outcome and gender attitude measures have been used widely (although most often as indicators in women's data) and are well understood attitudinal indicators. Also, our large sample size and international scope enabled us to focus exclusively on young men's attitudes and to examine a sparsely studied aspect of gender and fertility in a high fertility region. Given the critical role that men play in fertility, and their centrality in shaping and enabling women's empowerment in the household, these dynamics warrant further attention and analysis. To the extent that governments in East Africa aim to reduce fertility in their countries, they may need to address the cultural transmission of traditional masculine values in younger cohorts. Should they wish to, ministries can avail themselves of a growing number of programmatic interventions that encourage shared reflection on gender norms and values and that promote gender equality (Pulerwitz and Barker 2006; Solorzano et al. 2006; Jewkes et al. 2008a; Jewkes, Wood, and Duvvury 2008b; Ringheim 2010). Several of these interventions were conducted in sub-Saharan Africa (Snow 2000; Pettifor et al. 2007; Jewkes et al. 2008a; Jewkes, Wood, and Duvvury 2008b). 


\section{APPENDIX}

TABLE A1 Weighted percentage of men aged 15-24 who agree with individual components of three gender attitude indicators, five selected East African countries, 2004-07

\begin{tabular}{|c|c|c|c|c|c|}
\hline Characteristic & Ethiopia & Rwanda & Tanzania & Uganda & Zambia \\
\hline \multicolumn{6}{|l|}{ Wife-beating tolerance } \\
\hline \multicolumn{6}{|c|}{ Agrees that wife beating is justified if wife: } \\
\hline Goes out without telling him & 36.6 & 16.8 & 31.3 & 45.4 & 34.5 \\
\hline Neglects the children & 31.4 & 33.5 & 32.6 & 49.2 & 37.5 \\
\hline Argues with him & 31.3 & 3.3 & 29.3 & 41.8 & 33.0 \\
\hline Refuses to have sex with him & 25.1 & 10.9 & 20.1 & 21.1 & 19.0 \\
\hline Burns the food & 26.0 & 3.8 & 13.5 & 18.5 & 17.4 \\
\hline \multicolumn{6}{|c|}{ Decisionmaking authority } \\
\hline \multicolumn{6}{|c|}{ Final say on visits to family or relatives } \\
\hline Husband & 20.5 & 29.9 & 70.8 & 61.8 & 51.1 \\
\hline Wife & 5.9 & 22.8 & 4.4 & 14.6 & 9.3 \\
\hline Both equally & 66.2 & 38.6 & 23.0 & 21.4 & 37.4 \\
\hline Do not know & 7.4 & 8.7 & 1.7 & 2.1 & 1.9 \\
\hline Missing & 0.1 & 0.0 & 0.0 & 0.0 & 0.3 \\
\hline \multicolumn{6}{|l|}{$\begin{array}{l}\text { Final say on deciding what to do } \\
\text { with wife's earning }\end{array}$} \\
\hline Husband & 15.8 & 40.2 & 45.1 & 34.7 & 39.0 \\
\hline Wife & 22.5 & 19.9 & 31.9 & 43.9 & 27.2 \\
\hline Both equally & 53.1 & 34.9 & 19.1 & 20.3 & 31.5 \\
\hline Do not know & 8.4 & 5.0 & 3.9 & 1.1 & 2.0 \\
\hline Missing & 0.0 & 0.0 & 0.0 & 0.0 & 0.3 \\
\hline \multicolumn{6}{|c|}{ Final say on how many children to have } \\
\hline Husband & 13.1 & 18.1 & 46.9 & 50.7 & 47.5 \\
\hline Wife & 2.6 & 12.3 & 8.7 & 7.7 & 5.8 \\
\hline Both equally & 69.7 & 40.7 & 40.8 & 39.3 & 43.8 \\
\hline Do not know & 14.6 & 28.9 & 3.6 & 2.3 & 2.7 \\
\hline Missing & 0.1 & 0.0 & 0.0 & 0.0 & 0.3 \\
\hline \multicolumn{6}{|l|}{ Husband's sexual rights } \\
\hline \multicolumn{6}{|c|}{ If wife refuses sex, husband has right to: } \\
\hline Get angry & 22.8 & 31.6 & 54.9 & 43.4 & 40.8 \\
\hline Refuse financial support & 9.6 & 12.8 & 21.4 & 15.2 & 12.8 \\
\hline Use force for unwanted sex & 10.8 & 8.2 & 10.3 & 8.3 & 9.1 \\
\hline Have sex with another woman & 7.0 & 9.6 & 17.7 & 18.6 & 9.9 \\
\hline
\end{tabular}

NOTE: Missing cases and "do not know" responses are included in denominator for all proportions calculated in table. 


\section{REFERENCES}

Abrahams, Naeemah, Rachel Jewkes, Ria Laubscher, and Margaret Hoffman. 2006. "Intimate partner violence: Prevalence and risk factors for men in Cape Town, South Africa," Violence and Victim 21(2): 247-64.

Anand, Sudhir. 1994. "Population, well-being and freedom," in Gita Sen, Adrienne Germaine, and Lincoln C. Chen (eds.), Population Policies Reconsidered. Cambridge: Harvard University Press, pp. 75-105.

Bankole, Akinrinola. 1995. "Desired fertility and fertility behavior among the Yoruba of Nigeria: A study of couple preferences and subsequent fertility," Population Studies 49(2): 317-28.

Basu, Alaka M. 1999. "Women's education, marriage and fertility in South Asia: Do men really not matter?" in Catherine Bledsoe, John B. Casterline, Jennifer A. Johnson-Kuhn, and John G. Haaga (eds.), Critical Perspectives on Schooling and Fertility in the Developing World. Washington DC: National Academy Press, pp. 267-86.

Basu, Alaka M. and Gayatri B. Koolwal. 2005. "Two concepts of female empowerment: Some leads from DHS data on women's status and reproductive health," in Sunita Kishor (ed.), A Focus on Gender: Collected Papers on Gender Using DHS Data. Calverton, MD: ORC Macro, pp. 15-54.

Bawah, Ayaga Agula, Patricia Akweongo, Ruth Simmons, and James F. Phillips. 1999. “Women's fears and men's anxieties: The impact of family planning on gender relations in Northern Ghana," Studies in Family Planning 30(1): 54-66.

Bhushan, Indu and Kenneth Hill. 1996. “The measurement and interpretation of desired fertility,” Papers on Population WP 95-1. Baltimore, MD: Johns Hopkins Population Center.

Briere, John. 1987. "Predicting self-reported likelihood of battering: Attitudes and childhood experiences," Journal of Research in Personality 21(1): 61-69.

Carrington, Kerry and John Scott. 2008. "Masculinity, rurality and violence," British Journal of Criminology 48(5): 641-666.

Central Statistical Agency (CSA) [Ethiopia] and ORC Macro. 2006. Ethiopia Demographic and Health Survey 2005. Addis Ababa, Ethiopia, and Calverton, MD: CSA and ORC Macro.

Central Statistical Office (CSO) [Zambia], Ministry of Health, Tropical Diseases Research Centre, University of Zambia, and Macro International. 2009. Zambia Demographic and Health Survey 2007. Calverton, MD: CSO and Macro International.

Cleland, John and Christopher Wilson. 1987. "Demand theories of the fertility transition: An iconoclastic view," Population Studies 41(1): 5-30.

DeRose, Laurie F., Francis Ni-Amoo Dodoo, and Vrushali Patil. 2002. "Fertility desires and perceptions of power in reproductive conflict in Ghana," Gender \& Society 16(1): 53-73.

Diamond, Ian, Margaret Newby, and Sarah Varle. 1999. "Female education and fertility: Examining the links," in Catherine Bledsoe, John B. Casterline, Jennifer A. Johnson-Kuhn, and John G. Haaga (eds.), Critical Perspectives on Schooling and Fertility in the Developing World. Washington, DC: National Academy Press, pp. 23-48.

Dodoo, Francis Ni-Amoo. 2001. "Fertility preferences and contraceptive use: A profitable nexus for understanding the prospects for fertility decline in Africa." Workshop on Prospects for Fertility Decline in High Fertility Countries. New York: Population Division, Department of Economic and Social Affairs, United Nations Secretariat.

Dodoo, Francis Nii-Amoo and Ashley E. Frost. 2008. "Gender in African population research: The fertility/reproductive health example," Annual Review of Sociology 34(1): 431-452.

Ezeh, Alex Chika. 1993. "The influence of spouses over each other's contraceptive attitudes in Ghana," Studies in Family Planning 24(3): 163-174.

Ezeh, Alex C., Blessing U. Mberu, and Jacques O. Emina. 2009. "Stall in fertility decline in Eastern African countries: Regional analysis of patterns, determinants and implications," Philosophical Transactions of the Royal Society B: Biological Sciences 364(1532): 2991-3007. 
Flood, Michael and Bob Pease. 2009. "Factors influencing attitudes to violence against women," Trauma Violence Abuse 10(2): 125-142.

Frost, Ashley E. and Francis Nii-Amoo Dodoo. 2010. “The man comes to marry the woman': Exploring adolescent boys' gendered expectations for bridewealth and marriage among the Akwapim of Southern Ghana," Marriage \& Family Review 46(1): 41-59.

Garcia-Moreno, Claudia, Henrica A.F.M. Jansen, Mary Ellsberg, Lori Heise, and Charlotte Watts. 2005. WHO Multi-country Study on Women's Health and Domestic Violence against Women. Geneva: World Health Organization.

Haj-Yahia, Muhammad M. 2003. "Beliefs about wife beating among Arab men from Israel: The influence of their patriarchal ideology,"Journal of Family Violence 18(4): 193-206.

Heise, Lori L. 1998. "Violence against women: An integrated, ecological framework," Violence Against Women 4(3): 262-290.

Hollos, Marida and Ulla Larsen. 2004. "Which African men promote smaller families and why? Marital relations and fertility in a Pare community in Northern Tanzania," Social Science \& Medicine 58(9): 1733-1749.

Hunter, Mark. 2005. "Cultural politics and masculinities: Multiple-partners in historical perspective in KwaZuluNatal," in Graeme Reid and Liz Walker (eds.), Men Behaving Differently: South African Men Since 1994. Cape Town: Double Storey Books, pp. 139-160.

Inglehart, Ronald and Pippa Norris. 2005. Rising Tide: Gender Equality and Cultural Change Around the World. New York: Cambridge University Press.

Institut National de la Statistique du Rwanda (INSR) and ORC Macro. 2006. Rwanda Demographic and Health Survey 2005. Calverton, MD: INSR and ORC Macro.

Isiugo-Abanihe, Uche C. 1994. "Reproductive motivation and family-size preferences among Nigerian men," Studies in Family Planning 25(3): 149-161.

Jewkes, Rachel, M. Nduna, J. Levin, et al. 2008a. "Impact of Stepping Stones on incidence of HIV and HSV-2 and sexual behaviour in rural South Africa: Cluster randomised controlled trial," British Medical Journal 337: a506.

Jewkes, R., K. Wood, and N. Duvvury. 2008b. “I woke up after I joined Stepping Stones': Meanings of an HIV behavioural intervention in rural South African young people's lives," Health Education Research 25(6): 1074-1084.

Johnson, Kiersten and Yuan Gu. 2009. Men's Reproductive Health: Findings from Demographic and Health Surveys, 1995-2004. DHS Comparative Reports No. 17. Calverton, MD: ICF Macro.

Kishor, Sunita, ed. 2005. A Focus on Gender: Collected Papers on Gender Using DHS Data. Calverton, MD: ORC Macro.

Kishor, Sunita and Lekha Subaiya. 2008. Understanding Women's Empowerment: A Comparative Analysis of Demographic and Health Surveys (DHS) Data. DHS Comparative Reports 20. Calverton, MD: Macro International.

Lawoko, Stephen. 2008. "Predictors of attitudes toward intimate partner violence: A comparative study of men in Zambia and Kenya," Journal of Interpersonal Violence 23(8): 1056-1074.

Lichter, Erika L. and Laura A. McCloskey. 2004. "The effects of childhood exposure to marital violence on adolescent gender-role beliefs and dating violence," Psychology of Women Quarterly 28(4): 344-357.

Locoh, Thérèse. 1996. "Changements de rôles masculins et féminins dans la crise: La révolution silencieuse," in Jean Coussy and Jacques Vallin (eds.), Crise et population en Afrique: Crises économiques, politiques d'adjustement et dynamiques démographiques (Les Ėtudes du CEPED No.13). Paris: CEPED, pp. 445-470.

- 2002. "Structures familiales et évolutions de la fécondité dans les pays à fécondité intermédiaire d’Afrique de l'Ouest.” Population Division, Expert Group Meeting on Completing the Fertility Transition. New York: United Nations Secretariat.

Locoh, Therese and M. Mouvagha-Sow. 2004. “An uncertain future for African families." Paper presented at the International Family Change Conference, University of Michigan, Population Studies Center, June. 
Markowitz, Fred E. 2001. “Attitudes and family violence: Linking intergenerational and cultural theories," Journal of Family Violence 16(2): 205-218.

Ministry of Health (MOH) [Rwanda], National Institute of Statistics of Rwanda (NISR), and ICF Macro. 2009. Rwanda Interim Demographic and Health Survey 2007-08. Calverton, MD: MOH, NISR, and ICF Macro.

Murnen, Sarah K., Carrie Wright, and Gretchen Kaluzny. 2002. “If 'boys will be boys,' then girls will be victims? A meta-analytic review of the research that relates masculine ideology to sexual aggression," Sex Roles 46(11/12): 359-375.

National Bureau of Statistics (NBS) [Tanzania] and ORC Macro. 2005. Tanzania Demographic and Health Survey 2004-05. Dar es Salaam, Tanzania: NBS and ORC Macro.

Oyeyemi, G.M., A.A. Adewara, and R.A. Adeyemi. 2010. "Complex survey data analysis: A comparison of SAS, SPSS, and STATA," Asian Journal of Mathematics and Statistics 3(1): 33-39.

Pettifor, A.E., C. MacPhail, S. Bertozzi, and H.V. Rees. 2007 "Challenge of evaluating a national HIV prevention programme: The case of loveLife, South Africa,” Sexually Transmitted Infections 83(Suppl. 1): i70-i74.

Potts, Deborah and Shula Marks. 2001. "Fertility in Southern Africa: The quiet revolution,” Journal of Southern African Studies 27(2): 189-205.

Pulerwitz, J., G. Barker, M. Segundo, and M. Nascimento. 2006. "Promoting more gender-equitable norms and behaviors among young men as an HIV/AIDS prevention strategy." Washington, DC: Population Council. <http://www.popcouncil.org/pdfs/horizons/brgendernorms.pdf>. Accessed 20 November 2012.

Renne, Elisha P. 1993. "Gender ideology and fertility strategies in an Ekiti Yorubu Village," Studies in Family Planning 24(6): 343-353.

Ringheim, Karen. 2010. "Evaluation of the WHO training initiative-Transforming Health Systems: Gender and Rights in Reproductive Health, 1997-2007.” Geneva: WHO.

Rutstein, Shea O. 2008. “The DHS wealth index: Approaches for rural and urban areas.” DHS Working Paper No. 60. Calverton, MD: Macro International. <http://pdf.usaid.gov/pdf_docs/PNADN521.pdf $>$. Accessed 26 November 2010.

Rutstein, Shea O. and Guillermo Rojas. 2006. Guide to DHS Statistics. Demographic and Health Surveys. Calverton, MD: ORC Macro.

Sen, Amartya. 2005. The Argumentative Indian. New York: Picador, Farrar, Straus and Giroux.

Silberschmidt, Margrethe. 2001. "Disempowerment of men in rural and urban East Africa: Implications for male identify and sexual behavior," World Development 29(4): 657-671.

Snow, Rachel. 2000. "Operationalizing Cairo and Beijing: A training initiative in gender and reproductive health," Health and Human Rights 4(2): 227-34.

Snow, Rachel C., Massy Mutumba, Kenneth Resnicow, and Godfrey Mugyengi. 2013. “The social legacy of AIDS: Fertility aspirations among HIV-affected women in Uganda," American Journal of Public Health, 103(2): 278-85.

Solorzano, Irela, Rodolfo Pena, Oswaldo Montoya, Amy Bank, Mary Ellsberg, and Julie Pulerwitz. 2006. "Positive impact of an HIV prevention communication for social change program on youth.” Poster presented at the 16th International AIDS Conference, Toronto, Canada, 13-18 August. <http://www.popcouncil.org/pdfs/ TorontoPosters/nicsocchange.pdf $>$. Accessed 24 January 2013.

Steinmetz, S. and M.M. Haj-Yahia. 2006. "Definitions of and beliefs about wife abuse among ultra-Orthodox Jewish men from Israel,” Journal of Interpersonal Violence 21(4): 525-554.

Stephenson, Rob, Michael A. Koenig, and Saifuddin Ahmed. 2006. "Domestic violence and contraceptive adoption in Uttar Pradesh, India," Studies in Family Planning 37(2): 75-86.

Stewart, E.A., R.L. Simons. 2010. "Race, code of the street, and violent delinquency: A multilevel investigation of neighborhood street culture and individual norms of violence," Criminology 48(2): 569-605.

Tanzania Commission for AIDS (TACAIDS), Zanzibar AIDS Commission (ZAC), National Bureau of Statistics (NBS), Office of the Chief Government Statistician (OCGS), and Macro International. 2008. Tanzania HIV/ AIDS and Malaria Indicator Survey 2007-08. Dar es Salaam, Tanzania. 
Uganda Bureau of Statistics (UBOS) and Macro International. 2007. Uganda Demographic and Health Survey 2006. Calverton, MD: UBOS and Macro International.

United Nations Department of Economic and Social Affairs (UNDESA). 2011. World Population Prospects: 2010 Revision. <http://esa.un.org/wpp/Other-Information/faq.htm>. Accessed 14 September 2012.

Upadhyay, Ushma D. and Deborah Karasek. 2010. "Women's empowerment and achievement of desired fertility in Sub-Saharan Africa." DHS Working Papers No. 80. Calverton, MD: ICF Macro.

Westoff, Charles F. 2010. “Desired Number of Children: 2000-2008.” DHS Comparative Reports No. 25. Calverton, MD: ICF Macro.

Wilson-Williams, Lyndsey, Rob Stephenson, Sanjay Juvekar, and Karen Andes. 2008. "Domestic violence and contraceptive use in a rural Indian village," Violence Against Women 14(10): 1181-1198.

Woldemicael, G., 2007. “Women's status and reproductive preferences in Eritrea.” Working Paper 2007-023. Rostock, Germany: Max Planck Institute for Demographic Research.

\section{ACKNOWLEDGMENTS}

We would like to thank Kathy Welch and Brady West at the University of Michigan's Center for Statistical Consultation and Research (CSCAR) for their consultation and guidance regarding the analysis of complex sample survey data. We also appreciate the insights of our Ugandan colleague, Massy Mutumba, on the interpretation of the findings. 